\title{
Understanding Intelligence Studies
}

\author{
Ramesh Raj Kunwar \\ Department of Conflict, Peace and Development Studies, T. U. Nepal \\ kunwar.dr@gmail.com
}

\section{Article History}

Received September 15, 2020

Accepted October 17, 2020

\section{Keywords}

Intelligence, human intelligence, strategic intelligence, tourism and pandemic.

\section{Corresponding Editor}

Ramesh Raj Kunwar

kunwar.dr@gmail.com

\begin{abstract}
This paper contributes to the understanding of varieties of concept of intelligence and its application in broad academic and non-academic fields. This paper is an attempt to show that human's intelligence is a very important construct that is constantly being used to apply skills, knowledge and ideas in the fields of social, cultural, political, religious, spiritual, crisis, war and peace environment. The study of Intelligence teaches about the ways to get knowledge to become capable and to further enable individual, groups, and institutions to solve the problems for maintaining sustainability. The term Intelligence has a wide application and is used from micro to the macro level encompassing person, group, and the system. Furthermore, this construct is widely accepted and applied in wider area of health to military intelligence and also used in understanding emotional, cultural, and spiritual intelligence. Thus, the author considers that the study of various forms of intelligence could be an important contribution for the academic as well as the applied worlds.
\end{abstract}

Copyright@2021 Author

Published by: APF Command and Staff College, Kathmandu, Nepal ISSN 2616-0242 


\section{Introduction}

The term intelligence is originated from a Latin word that originally meant to perceive, comprehend and was linked to several general abilities of the person that will ultimately help one to survive or adjust in the environment. Thus, intelligence is not a new topic to study and also not only confined with psychological inquiry and its measurement. Even after decades of studies and variety of definitions based on theories and psychometric measurements, experts still continue to listen to the classic tale of four blind men and an elephant to understand intelligence. However, people who have seriously started to understand intelligence were not psychologists or educators as many considered them to be but actually are philosophers like Plato of ancient-Greek who 'linked people's intelligence to blocks of wax, differing in size, hardness, moistness, and purity’(Cianciolo \& Stenberg, 2004).

In the very beginning, Intelligence Studies came out from psychological studies. Psychologists have developed number of theories which are unique on their own. Though this study has been highlighted by many psychologists, the present author has visited the theory of Gardner, Bandura, and Sternberg. Studies on intelligence have been expanded in diversified areas and their various related agencies are recognized by many organizations. Realizing the importance, many disciplinarians have applied the 'intelligence' studies in various academic fields. The objective of writing this paper is to highlight the importance of intelligence in the academia which will be useful in understanding intelligence and its applications in difficult times for the solution.

Interestingly, in the course of studying intelligence, some people raise the questions of whether intelligence is same as the terminologies like intelligentsia, intellectual and diligent. Intelligence has been defined in many ways as per the differences in the capacity of understanding, self-awareness, learning emotional knowledge, reasoning, planning, creativity, critical thinking, problem-solving, adapting and adjusting. Generally, it can be described as the ability to perceive or infer information, and to retain it as knowledge to be applied towards adaptive behaviors within an environmental context (Dumper, Jenkins, Lacombe, Lovett, \& Perimutter, n.d.).

More recently, the Triarchic theory (1985) has been updated and renamed as the "Theory of Successful Intelligence" by Sternberg $(1978,2003)$. One way to seek understanding of intelligence is to simply define what it is. Intelligence is an individual's assessment of success in life by the individual's own (idiographic) standards and within the individual's sociocultural context. Success is achieved by using combinations of analytical, creative, and practical intelligence. Sternberg (1986) purports two principal classifications of definition of intelligence - the "operational" definition and the "real" definition. Operational intelligence is measurable while the Real intelligence is the one that inquires the true nature of the thing being defined. Numerous theories of intelligence has been derived on the basis of plethora of definitions of intelligence. 
Anthropologist Ulf Hannerz (1992, p.140; in Trembath, 2017) pondered this in his book Cultural Complexity: Studies in the Social Organization of Meaning, way back in 1992, before the current climate of distrust in experts was heated. Hannerz lays out what he (and others upon the home he draws) see as the difference between the intelligentsia, who are discipline experts, and intellectuals, who are the critical tAhinkers who transcend disciplinary bounds. The intelligentsia solve problems within the paradigm they have been trained with. Intellectuals also aim to solve problems by processing ideas and meanings, but are more likely to draw them from multiple disciplines.

Hannerz describes the role of the intellectual in detail. According to his description, it is the business of intellectuals to carry on traffic between different levels of meaning within a culture, to translate between abstract and concrete, to make the implicit and the certain questionable, to move ideas which usually thrive on separateness, to seize on inconsistency, and to establish channels between different modes of giving meanings external shape (Hannerz, 1992, p.140; in Trembath, 2017). An intellectual is a person who engages in works by intellect including critical thinking and reading, research, writing, and human self- reflection about society...artistic or creative output, such as writing, composing, music, painting and so on (Intellectual, n.d.).

The intelligentsia is a status class of educated people engaged in the complex mental labors that critiques, guides, and leads in shaping the culture and politics of their society. As a status class, the intelligentsia includes artists, teachers and academics, writers, and the hommes de lettres (Raymond 1983, p. 170). The definition of diligent is hard working and done with painstaking effort. An example of diligent is worker who always stays late to get projects done on deadline ("Your Dictionary," n.d.). For psychologists, the primarily goal of the study of intelligence was to find the difference in abilities, measure it and when possible to increase it with different biological, psychological and social means. The term intelligentsia, intellectual, and diligence are linked to general and specific abilities.

Moving slightly from the die-hard psychometric notion of intelligence, Sternberg (1986) developed a triarchic theory of intelligence which comprises three types of intelligence commonly known as practical intelligence, creative intelligence, and analytical intelligence, producing transformative insights and technologies require what Sternberg (1996) calls "successful intelligence". Creative intelligence is required to formulate ideas and solutions to problems. Analytical intelligence is required to solve problems and to evaluate the quality of ideas. And lastly, Practical intelligence is needed to apply the ideas in an effective way, says Sternberg, intelligence is the balance among these three ways of thinking. It means knowing how and when to use these aspects of successful intelligence rather than just having them (p.128; in Repko, 2012, p.39). Early research tended to view intelligence narrowly as the ability to solve problems in the academic settings, there is now increasing consensus that intelligence may be displayed in places other than the classroom (Sturnberg \& Detterman,1986; in Ang et al., 2007). The interest in 'real world' intelligence includes intelligence that focuses on specific content domains such as social intelligence (Thorndike \& Stein, 1937; in Ang et al., 2007) and practical intelligence (Sternberg et al., 2000; in Ang et al., 2007). 
Studies in intelligence will be useful to the students of all disciplines. Although this area has been predominated by psychology, at present, the study of intelligence has been expanded to the new fields of security, conflict management, international relations, cross cultural studies, strategic studies, religion, business studies, tourism, information, communication and technologies. It is studied now through plural-disciplinarian perspectives that sheds more lights on its importance in not only understanding humans' ability but also collecting of information and the capacity to solve the problems and expanding from individual level from everyday life to family, culture, religion, education, safety, security, business for increasing knowledge, ability, decision making with policy and planning. The term intelligence is a kind of survival strategy of human beings. This paper highlights that the intelligence study should not be confined to only one subject because the literatures show that it has sufficient scopes in various levels and aspects of humans' behavior in relation to variety of purpose and settings. This study includes introduction, theoretical approaches, diversified areas of intelligence studies, review and methods, intelligence studies in Nepal and conclusion.

\section{Review and methods}

Aiming to offer a comprehensive reference for readers from different disciplines, this article accumulates profound knowledge of intelligence in a better way. The primary provocation of this research is an output of author's wide-ranging insights and experiences that came from various academic positions in Nepal Army and Armed Police Force. As a scholastic achievement, author completed Strategic Studies at NESA (Near East South Asia), USA and taught at Nepalese Military Academy for 11 years, at Army Command and Staff College for 20 years and at the Department of Conflict, Peace and Development Studies, TU for 12 years.

Procedurally, this study has fallen in descriptive research design approach and followed umbrella review. Review is defined as 'to view, inspect, or examine a second time or again' (Oxford English Dictionary, 2008; in Grant \& Booth, 2009, p. 92, 107). Reviewed articles can cover wide subject matter at various level of completeness and comprehensiveness based on analysis of literature that may include research findings (Grant \& Booth, 2009, p.97). Review papers provide platforms for new conceptual frameworks, reveal inconsistencies in the extant body of research, diverse the results, and generally give other scholars a "state of art" snapshot of a domain often written by topic experts (Bem, 1995; in Palmatier, Houston, and Hulland, 2018). Umbrella review refers to compiling evidences from multiple reviews into one accessible usable document. It focuses on broad conditions or problems for which there are competing interventions and highlights reviews that address these interventions and their results (Grant \& Booth, 2009, p.95). This research is essentially exploratory (preliminary research for clarifying the nature of the problem to be solved), and therefore, the methods employed in this study are primarily qualitative. Exploratory research can add quality and insightful information and is vital to the study. In order to get the information, the author collected the secondary sources from Google Search. Basically, research based books, journal articles and newspaper articles on intelligence studies also became the major sources in this study. 


\section{Multiple intelligence theories}

Among researchers who have identified various types of intelligence, Gardner's (1993; in Vaughan, 2002) pioneering work on multiple intelligence is multifaceted. His research indicates that different kinds of intelligence develop relatively independently to each other, and proficiency in one area does not imply proficiency in the other. It is Cattell (1963) who proposed a theory of intelligence that divided general intelligence into two components: (1) crystallized intelligence; and (2) fluid intelligence. Crystallized intelligence is acquired and is the ability to relieve it. Fluid intelligence encompasses the ability to see complex relationships and solve problems (Cattell, 1963; in Pal, Pal, \& Tourani, 2004). In course of studying intelligence, Gardner (1983) developed a multiple intelligence theory under which he categorized eight different intelligences which are: linguistic intelligence, logical- mathematical intelligence, musical intelligence, bodily kinesthetic intelligence, spatial intelligence, interpersonal intelligence, intrapersonal intelligence, and naturalist intelligence.

Major intelligence theories are broadly grouped into four main types: (1) psychometric theories; (2) cognitive theories; (3) cognitive- contextual theories; and (4) biological theories. Psychometric theories are derived from studying individual differences in their performance on cognitive tests. Questions about the structure of human intelligence, including the importance of general intelligence, have dominated the psychometric theories. Cognitive theories are derived from studying the processes involved in an intelligence performance. These processes range from the very simple (e.g. inspection time) to the fairly complex intelligence (e.g. Working memory).Cognitive- contextual theories emphasize processes that demonstrate intelligence within a particular context (such as a cultural environment). Major theories include Sternberg's triarchic theory, Gardner's theory of multiple intelligences, and Piaget's theory of development. Biological theories emphasize the relationship between intelligence, the brain and its functions (Gardner, 2011). In this study the author has incorporated all the above mentioned four intelligence theories covering the form of intelligence, individual and competencies; intelligence studies in diverse areas (emotional intelligence, cultural intelligence, spiritual intelligence, tourism and artificial intelligence, Military intelligence, and pandemic and intelligence); intelligence around the world and intelligence studies in Nepal.

\section{Intelligence, individual and competencies}

In this sub-topic, the author discusses the concept of intelligence being applied in other human functioning areas that directly or indirectly raise the qualities of the individual while dealing with other people, ideas, and settings. Considering the success of intelligence quotient (IQ) and its application in human quest for control over self, other, and the larger group, new vocabularies with a range of quotients-along with IQ, Emotional Quotient (EQ), Cultural Quotient (CQ), Adversity Quotient (AQ), Positive Quotient (PQ) and Spiritual Quotient (SQ) have emerged. The IQ is a quantitative or statistical representation of an individual's score on a standardized intelligence test (Jeffery, Deluca, \& Caplan, 2011). EQ is the ability to understand, use and manage one's own emotions in 
positive ways to relieve stress, communicate effectively, empathize with others, overcome challenges and defuse conflict (Segal, Smith, Robinson, \& Shubin, 2019). Meanwhile, CQ is a term used in business, education, government and academic research. It can be understood as the capability to relate and work effectively across various cultural groups. Originally the term was developed by Christopher Earley (2002) and Earley and Soon Ang (2003). Later on, Soon Ang and Linn Van Dyne worked on a scale development of the CQ construct as a researched-based way of measuring and predicting inter cultural performance.

Psychologists indicate that life success depends $20 \%$ on IQ and $80 \%$ on EQ and AQ, collectively known as "3Q". EQ means abilities to perceive access and manage the emotions of one's self and of others, including identifying emotions (Diffen, n.d.) Positive intelligence is an indication how well your mind acts in your best interest. (Meier, 2012). SQ is defined as the intelligence with which we address and solve problems of meaning and value, the intelligence with which we can place our actions and our lives in wider, richer, meaning giving context, the intelligence with which we can assess that one course of action or one life-path that is more meaningful than any other (Chippendale, 2001).

IQ is the minimum level of ability that one needs to get a job, but AQ is how you will be successful over time. AQ involves flexibility, curiosity, courage, resilience and problem-solving skills (Murray, 2019). EQ is defined as an individual's ability to identify, evaluate, control, and express emotions. People with high EQ usually make great leaders and team players because of their ability to understand, empathize, and connect with the people around them. IQ is a score derived from one of the several standardized tests designed to assess an individual's intelligence (Diffen, n.d.). One of the functions of IQ test and the measured level is to determine academic abilities and identify individuals with off-the-chart intelligence or mental challenges. EQ is a better indicator of success in the workplace and is used to identify leaders, good team players, and people who best work by them. (Diffen, n.d.)

\section{Intelligence studies in diverse areas}

When intelligence studies became very popular in the academia, scholars of different disciplines made efforts to highlight the significance of intelligence studies in numerous fields that attracted many interdisciplinary researchers.

\section{Emotional intelligence}

Emotional intelligence includes the ability to be self-aware of one's emotional state, to make meaning of emotional reactions, and to regulate and manage emotional reactions (Mayer \& Salovey, 1990). Exploration of the meaning and measurement of emotional intelligence has been of intensifying interest in the educated communities.

Mayer, Salovey, and Caruso (2004) identified four primary components related to emotional intelligence: 1) perception of emotions, 2) facilitating thought processes through 
the use of emotion, 3) emotional understanding, and 4) the ability to effectively manage emotions. Emotional intelligence is positively correlated with positive social relationships with others and negatively associated with aggression and violence towards others. Higher emotional intelligence suggests someone less likely to engage in personally self-destructive, violent, or addictive behaviors (Mayer, Salovey \& Caruso, 2004). Goleman (1995; in Mayer, Salovey, \& Caruso, 2004) suggested five dimensions of emotional intelligence that include: 1) self-identification of emotions; 2) Handling emotions in an appropriate manner; 3) Using emotions in an appropriate and productive manner; 4) ability to understand the emotions of others; and 5) Ability to develop effective relationships. Goleman's list specifically incorporated the aspects of relationship in addition to the dimensions similar to those described by Mayer, Salovey and Caruso (2004).

Emotional regulation can occur at different levels of consciousness and the mechanism of regulation will match the consciousness level. Basic emotional orientation will be enacted at a non-conscious level of emotional regulation. At a low level of consciousness, the mechanism will be characterized by both an open acceptance of the flow of emotion as well as an ability to view the situation from a perspective that disposes the emergence of both appropriate and effective emotions. At the highest level of consciousness, emotions are managed through keen self-observation and moral aplomb (Mayer \& Salovey, 1995).

Recently, researchers have promoted the idea that our notion of intelligence should be expanded to include EQ which has generally been defined as the ability to perceive, understand and manage one's emotion (Salovey, Hsee, \& Mayer, 1993; Salovey \& Mayer 1990; in Ciarrochi, Amy, \& Chan, 2000). The notion of EI was first introduced by Salovy and Mayer in 1990 and since then has become enormously popular. Salovery and Mayer (1990) defined EI as the ability to appraise, express, and regulate emotions (in self and others), and the ability to utilize emotions (e.g., to harness emotions to solve problems). Emotional intelligence is the best predictor of success in life, redefining what it means to be smart (Time, 1995), and that EI will confer ' $\ldots$ an advantage in any domain in life, whether in romance and intimate relationships or picking up the unspoken rules that govern success in organizational politics' (Goleman, 1995, p.36; in Ciarrochi et al., 2000). Goelman's (1995; in Voughan, 2002, p.18) research on emotional intelligence, based primarily on intrapersonal and interpersonal intelligence, indicates that success in many areas of life depends on emotional skills as much as on cognitive capacities. Emotional intelligence includes self-awareness and self- control, as well as the ability to get along well with others. The major areas of emotional intelligence are: emotion perception regulation understanding and utilization. In addition, Gardner (1993; in Voughan, 2002) discussed kinesthetic intelligence that enables a person to use the body in highly differentiated and skilled ways, such as dance or athletes; musical intelligence necessary for all different kinds of musical aptitude; intrapersonal intelligence that implies awareness of one's own thoughts and feelings; and interpersonal intelligence that enables us to relate to others empathetically (Voughan, 2002). Emotional intelligence implies an ability to listen to communicate, to accept feedback, and to emphasize with different points of view. 
Cultural intelligence

CQ is an ability to adapt to new cultural settings. It is defined as a multifaceted competency consisting of cultural knowledge, the practiceofmindfulness, and the repertoire of behavioral skills (Thomas \& Inkson, 2004, pp.182-183; in Crowne, 2013). It is considered a capability that allows individuals to understand and act appropriately across a wide range of cultures (Thomas, 2006; in Crowne, 2013). According to Early and Mosakowski (2004), CQ is 'an outsider's seemingly natural ability to interpret someone's unfamiliar and ambiguous gestures the way that a person's compatriots would. CQ has 3 key components i.e., Head, Body and Heart. (1) Head is the knowledge and understanding that an individual dealing with people from different cultural group need good CQ. This can be achieved by observation, comprehension of the meaning and symbols, and the context. Knowledge and understanding of what and how behavior is being constructed, represented and shared socially can be an important asset while communicating with cultural group. (2) Body means translating cultural information into visible actions that is observable to cultural group. Gesture and body language always carries a specific meaning, significant in each culture. (3) Heart or having a high CQ. To gain a high $\mathrm{CQ}$, one needs to be self-assured, confident and always learning to improve the multicultural skills to deal with new cultural situations. Cultural intelligence is widely researched and practiced in business and organizational areas where success is always linked to effective and appropriate communication and understanding of culture.

Individual intelligence, emotional intelligence and cultural intelligence are the perfect combination for personal and organizational success. All intelligence in fierce competitive organizational, socio-cultural, and political world complements each other. A person with high level CQ can appropriately understand the cultural belief, values, and behavioral patterns and with EQ can skillfully relate emotionally in their interpersonal communication and finally with moderate or high level of cognitive ability (IQ) can deal with successfully with person or group.

Spiritual intelligence

Wigglesworth (2014) defines spiritual intelligence as "the ability to act with wisdom and compassion, while maintaining inner and outer peace, regardless of the circumstances" (Wagglesworth, 2014). King \& DeCicco (2009) have defined spiritual intelligence as a set of adaptive mental capacities based on non-material and transcendent aspects of reality, specifically those that: “ ...contribute to the awareness, integration, and adaptive application of the nonmaterial and transcendent aspects of one's existence, leading to such outcomes as deep existential reflection, enhancement of meaning, recognition of transcendent self, and mastery of spiritual states"(Koenig, McCullough, \& Larson, 2000). Kumar and Mehta defined spiritual intelligence as the capacity of an individual to possess a socially relevant purpose in life by understanding "self " and having a high degree of conscience, compassion and commitment to human values" (2011). King further proposes four core abilities or capacities of spiritual intelligence: (1) Critical Existential Thinking; (2) Personal Meaning Production; (3) Transcendental Awareness; and (4) Conscious State Expansion (King \& DeCicco, 2009). 
Vaughan (2002) describes spiritual intelligence as concerned with the inner life of mind and spirit and its relationship to being in the world. Spiritual intelligence implies a capacity for a deep understanding of existential questions and insight into multiple levels of consciousness. Spiritual intelligence also implies awareness of spirit as the ground of being or as the creative life force of evolution.

If the evolution of life from stardust to mineral, vegetable, animal, and human existence implies some form of intelligence rather than being a purely random process, it might be called spiritual. Spiritual intelligence emerges as consciousness evolves into an ever- deepening awareness of matter, life, body, soul, and spirit.

SQ is one of the several types of intelligence that calls for multiple ways of knowing and for the integration of the inner life of mind and spirit with the outer life of work in the world. It is a capacity for developing meaning, vision and value. Spiritual intelligence is more than individual mental ability. It appears to connect the personal to the transpersonal and the self to spirit. Spiritual intelligence is also defined in relation to self-actualization and WHO (2001) has pointed out the importance of spiritual intelligence in mental health in addition to the physical, mental and social dimensions. The predictive role of spiritual intelligence has been emphasized not only in improving mental health, but as an important factor in the process of treating mental health conditions (Elkins et al., 1988).

Spirituality exists in the hearts and minds of men and women everywhere, within religious traditions and independently of tradition. However, the term ultimate concern can be interpreted in many different ways. Spirituality, like emotion, has varying degree of depth and expression. It may be conscious or unconscious, developed or undeveloped, healthy or pathological, naive or sophisticated, beneficial or dangerously distorted (Vaughan, 2002, p.17). Frances Vaughan (2002) offers the following description: Spiritual is concerned with the inner life of mind and spirit and its relationship to being in the world. Some current definitions of spirituality can be summarized as follows: (a) Spirituality involves the highest levels of any of the developmental lines, for example, cognitive, moral, emotional, and interpersonal; (b) spirituality is itself a separate developmental line; (c) spirituality is an attitude (such as openness to love) at any stage; and (d) spirituality involves peak experiences not stages. An integral perspective would presumably include all these different views, and others as well (Wilber, 2000; in Vaughan, 2002, p.17).

Tourism and artificial intelligence

AI is transforming our lifestyle intending to mimic human intelligence by a computer/machine in solving various issues. Initially, AI was designed to overcome simpler problems like winning a chess game, language recognition, image retrieval, among others. With the technological advancements, AI is getting increasingly sophisticated at doing what humans do, but more efficiently, rapidly, and at a lower cost in solving complex problems. AI in healthcare provides an upper hand undoubtedly over traditional analytics and clinical decision making techniques. In computer science, AI, sometimes called machine intelligence, is intelligence demonstrated by machines, in 
contrast to the natural intelligence displayed by humans and animals. In the previous literature of tourism, artificial intelligence is mainly used to estimate tourist arrivals and forecasting the economic development in the future (Claveria \& Torra, 2014; Stalidis et al., 2015; Asadi et al., 2016), Machine learning (ML) algorithms, a subset of AI, can detect patterns from huge complex datasets to become more precise and accurate as they interact with training data, allowing humans to gain unprecedented insights into early detection of diseases, drug discovery, diagnostics, healthcare processes, treatment variability, and patient outcomes (Jianj, Jianj, \& Zhi, 2017; in Dananjayan, \& Raj, 2020).

Currently the focus has shifted to technological applications in tourism and new sectors in tourism such as smart tourism (Genç, 2020). Early approaches to intelligent systems in tourism mostly focused on expert systems providing support for tourism industry professionals (Hruschka \& Mazanec, 1990; Loban, 1997; in Gretzel, 2011, p. 759). Nowadays, intelligent systems in tourism are typically envisioned as fully autonomous travel counselors or concierges that have the ability to determine user preferences and anticipate user needs while having a large and at the same time specialized knowledge repository at their fingertips and continuously evaluate their suggestions based on feedback received from their users (Venturini \& Ricci, 2006; in Gretzel, 2011). Intelligent systems in tourism are also developed to provide functions traditionally offered by tour operators and travel guides, such as travel planning/scheduling tasks, navigation and interpretation (Kramer, Modsching, \& ten Hagen, 2007; in Gretzel, 2011).

Smart tourism is defined as a new social, cultural and economic activity where people move to other countries and places outside of their daily environment for a personal or professional aim (UNWTO, 2015; in Genç, 2020). Like smart city applications, smart tourism has rapidly become an important economic activity that is capable of promotinglocaldevelopmentand otherindustries in theregion(Ren, 2013; in Genç, 2020). The activity of smart tourism is connected to technological infrastructure, promotion of Wi-Fi, development of mobile applications, a new understanding of management as well as taking a new attitude for data collection and analysis (Gretzel et al., 2015). The name "smart" and "intelligence" was used interchangeably in the previous literature, denoting the same meaning that consists of wide use of technological entities despite essential differences between the terms of smart tourism and intelligence tourism (Li et al., 2017 in Genç, 2020) which was started after 2011(Zhu, Zhang, \& Li, 2014; in Genç, 2020).

\section{Military intelligence}

Intelligence activities, defined as including the process of data collection and knowledge analysis for decision making by the military and governmental hierarchies, are perceived as serving three goals:(a) evaluation of the rival's capabilities and intentions; (b) enhancing the capability of the military by increasing effectiveness of its weapon systems and reducing the effectiveness of rival's weapon systems; (c) intelligence superiority yields an advantage over the rival, particularly with respect to deterrence and preemption. From time immemorial intelligence has been a key factor in security planning, as shown notably 
by the biblical story of the twelve spies and Sun Tz'u's treatise The Act of War. Most definitions of military intelligence share three components: processed information, time relevancy and policy-making decisions. Scholars agree that military intelligence aims at ensuring national security during peace and war times and should be based on governmental (or military) agency (see in detail Clark, 2007; in Pecht \& Tishler, 2011, p.3).

Intelligence study invites another aspect which is known as strategic intelligence and strategic intelligence analysis. There are three levels in this intelligence study: strategic, tactical (operational, or combat) and counter intelligence. Among these three levels, the strategic intelligence includes information about the capabilities and intentions of foreign countries. In strategic intelligence, information is needed to formulate policy and military plans at the international and national policy levels. Strategic intelligence encompasses aggregation of different types of intelligentsia that creates synergy in an organization's intelligence and knowledge management to facilitate acquisition of valuable information of that play a crucial role in organizational decision making process (Study Mosse, 2015).

Sociological intelligence is useful to a military intelligence system because sociological concepts are keys to understanding a region's stability, military capability and foreign policy (Richelson, 1999).The importance of sociological intelligence has been demonstrated most prominently in recent conflicts in the former Yugoslavia, Arica, Russia, and Middle East. Espionage is a process of obtaining military, political, commercial or other secret information by means of spies, secret agents or illegal monitoring devices. Espionage is sometimes distinguished from the broader category of intelligence gathering by its aggressive nature and its illegality (Espionage, 2017)

Strategic intelligence analysis as a "specific form of research that addresses any issue at a level of breadth and detail necessary to describe threats, risks, and opportunities in a way that helps to determine programs and policies"(McDowell, 2009; in Olsen, 2009).As such, strategic intelligence analysis is distinctly different from, but complementary to tactical or operational intelligence analysis, which are focused on specific targets or individuals and support the day-to-day activities or operational line units (Oleson, 2009).

Tactical intelligence is information required by military field commanders so they can make plan for, if necessary conduct for operations. Military intelligence is a military discipline that uses information collection and analysis approaches to provide guidance and direction to assist commanders in their decisions. Areas of study may include the operational environment, hostile, friendly and neutral forces, the civilian population in an area of combat operations, and other broader areas of interest (SetonHall University, 2011/2012)

Security intelligence capacities are directed to a variety of aims, all of which involve the constitution of various types of security networks. Networks are constituted by the media that link its various nodes, that is, by the various exchanges, movements, or flows of information, goods and services that connect its otherwise isolated or segmented points. In terms of information flows, the development of ICTs (information and communication 
technologies) has been instrumental in opening new communication channels between previously isolated agents (Dupont, 2004; in Lippert \& O'Conner, 2006). In the context of security networks, we define security intelligence as a process that includes the coercive or covert acquisition of data about security issues, events, and responses. Data are singularities or events - they exhibit qualities that are independent of their relation to other things and qualities (Shields et al., 2002, p.143; in Lippert \& O'Conner, 2006, p.53).Security data represent the everyday /every-night experiences and routines (Smith, 1999; in Lippert \& O'Conner, 2006) and informal decision- making capacities of security agents within local communities of practice. In a security intelligence network, nodes are constituted and connected by the medium of intelligence. Through its dissemination, security intelligence is used to both authorize and direct security to the benefit of security stakeholders (Shearing \& Wood, 2000, in Lippert \& O’Conner, 2006).

Among the major issues, some of concern are: centralization vs. decentralization of intelligence agencies; advantage and disadvantages of inter- and outer- military intelligence efforts, and the level of redundancy among the various security agencies. Pecht and Tishler (2011, FN.7) view that all the intelligence agencies are one entity. The main benefits of military intelligence can be classified under three main headings: the evaluation effect, the operational effect, and the relative effect. The evaluation effect is influenced by two attributes: (a) the degree of uncertainty - the decision maker's conservatism and (b) intelligence process or intelligence efficiency. The operational effect is characterized by the knowledge collection which enhances the capability of the country's military that analyses or evaluates on effectiveness of weapon systems used technically that requires technical intelligence. The relative effect is based on how the country has intelligence superiority over the rival and its consequences are the leader show the willingness to enter into a conflict (Pecht \& Tishler,2011).Intelligence activities are conducted at all levels, from tactical to strategic, in peace time, the period of transition to war, and during a war itself (IBP, 2016).

\section{Pandemic and intelligence}

There was a pneumonia case with an unknown cause detected on 17 November, 2019 in Wuhan, a city of Hobei province of China. The first case of coronavirus infection in human was identified on 31 December, 2019 in Wuhan. Therefore, to control the infection, the central government of China imposed a lockdown in Wuhan and other cities of Hobei on 23 January, 2020. However, the virus spreads rapidly from Wuhan to other cities of China and crossed its national borders; hence, WHO declared Public Health Emergency of International Concern (PHEIC) on 30 January, 2020. Similarly, on 11 February, 2020, WHO announced that the disease caused by novel coronavirus would be named COVID-19. Following the best practices, the name of the disease was chosen to avoid inaccuracy and stigma; therefore, the name COVID-19 did not refer to a geographical location, an animal, an individual or group of people. On 11 March 2020, COVID-19 was declared as pandemic outbreak throughout the world by WHO. Wuhan, China lifted the lockdown on 8 April 2020; however, it dramatically spread globally and the virus infected many people in the world. As of September 21, 2020, the latest data of WHO (2020) shows that the 
corona virus pandemic confirmed cases are 30,905,162 including 958,703 deaths. Likewise, in the case of Nepal, the confirmed cases recorded till September 21, 2020 as per Worldometer (2020) are 65,276 including 427 death cases and 47,238 recovered so far.

A 'pandemic' is when a disease becomes widely prevalent across a country or multiple countries. The preference to use 'pandemic' is for multiple country disease outbreaks, and to use 'epidemic' is for single country or country sub-region outbreaks. The MERS outbreak is considered an epidemic, whereas the two SARS outbreaks were considered pandemics. Pandemic is the form of epidemic that spreads through human population affecting large numbers of people, major part of a nation, entire nation, a continent or a part of the entire world (Samal, 2014, p.165). The COVID-19 pandemic emerged into a world that was seeing rapid developments in artificial intelligence (AI) based on big data, computational power and neural networks. In recent years, the gaze of AI researchers has increasingly turned to applications in healthcare. The COVID-19 pandemic has presented numerous challenges to virtually every section of society in all geographic locations (Hu, Jacob, \& Stoyanov, 2020).

During the recent global urgency, scientists, healthcare experts, and clinicians around the globe keep on searching for a new technology to support in tackling the COVID-19 pandemic. They used technologies like AI, Internet of Things (IoT) Big Data and Machine Learning to fight and look ahead against the new disease. They believed that AI is one of such technology which can easily track the spread of the virus, identify the high risk patients, and is useful in controlling this infection in real time. AI will be helpful to fight this virus by population screening, medical help, notification, and suggestions about the infection control (Bai, Hsieh, Xiong et al,2020; Hu, Gejin, \& xiom 2020; in Vaishya, Javaid, \& Haleem, 2020).The physician is not only focused on the treatment of the patient, but also the control of disease with the AI application. Major symptoms and test analysis are done with the help of AI with the highest accuracy. Vaishya, Javaid, \& Haleem (2020) have identified seven significant applications of AI for Covid-19 pandemic which are as follows: Early detection and diagnosis of the infection; Monitoring and treatment; Contact tracing of the individuals; Projection of cases and mortality; Development of drugs and vaccines; Reducing the workload of health workers; and Preventions of the disease.

People of the 21st century live in a wired world and despite being geographically dispersed, they are connected by technology. Within a click of their mouse or a touch of their finger, they access information on social media such as Twitter, Facebook, WhatsApp, and Instagram inter alia, which are also vehicles for fake news and disinformation (Larson, 2018; in Gowreesunkar, 2020). A number of social media platform and famous international companies including Google, Amazon, YouTube and Twitter, attended a meeting in early February hosted by the World Health Organization, at Facebooks's offices. The aim was to fight the "infodemic" of rumors, myths and misinformation related to COVID-19. Following the meeting, numerous platform responded by setting up system in an attempt to spread correct information. Google launched and SOS Alert system which makes WHO coronavirus resources more easily accessible when "coronavirus" is searched by using Google. 
In the digital age, the time needed to analyze access and communicate information cannot compete with the instantaneous spreading of misinformation on social media platforms. Societies and communities worldwide should therefore avoid spreading rumors on social media; erroneous and misleading information cause panic and instigate communal bias. It is not the time to discuss region and religion of the COVID- 19 pandemic, rather it is the time to join hands and collectively fight it as one community and one identity (Gowreesunkar, 2020). YouTube has added a banner redirecting users to the WHO web portal on all videos that discuss COVID- 19. Facebook has additionally launched a "Community Help" feature where people can volunteer to donate to fundraisers. It has also banded ads and listings for medical-grade face masks, and has given the WHO unlimited free ad space. Snapchat worked with WHO to create filters that display facts on how to stay safe and social distance. These filters include reminders to wash your hands, cover your face when you sneeze and stay home. WhatsApp has worked with WHO to create a Health Alert system that is designed to answer question from the public about COVID- 19 and provides prompt, reliable and official information 24 hours a day and worldwide. This feature has been made available in all six of United Nations languages. The WHO also launched a similar system with Viber (Gowreesunkar, 2020).

The Pandemic Health Plan provides a framework for collecting the information required to support decision making about COVID-19. The Pandemic Health Plan is designed to inform decisions on adjusting the measures in place to suppress the spread of COVID-19 in Australia. Both intelligence and surveillance were used for getting readiness to adjust restrictions and the outcome of changes that they made. The plan includes four broad intelligence inputs known as Epidemiological situation (monitoring number of cases, ages, severity, source of acquisition where they are located, and changes over time); Public health system capacity (monitoring how fast cases are detected and isolated, and contacts are traced and quarantined to reduce transmission); Health care system capacity (with lower cases numbers, the opportunity to resume more normal health care activities); Community acceptance and adherence (effectiveness of measures depends on the community understanding, accepting and following public health advice and the plan includes how well the public is adhering to health guidance including community attitudes, transport and traffic movements, and movement data) (Australian Government, Department of Health, 2020).

WHO has distinguished between quarantine and isolation on 18 March, 2020 where governments use quarantines to stop the spread of contagious diseases. Quarantines are for people or groups who don't have symptoms but were exposed to the sickness; keep them away from others so they don't unknowingly infect anyone. Similarly, isolation is used to separate ill or infected persons from those who are healthy and restrict their movement to prevent spread of contagious diseases. Isolated patients are treated in a hospital setting and receive medical care as need. Quarantines may be used during;

- $\quad$ Outbreaks: When there's a sudden rise in the number of cases of a disease.

- $\quad$ Epidemics: Similar to outbreaks, but generally considered larger and more wide spread.

- $\quad$ Pandemics: Larger than epidemics, generally global in nature and affect more people (Medical Laboratory Technologist, 2020). 
Dananjayan and Raj (2020) argue that both basic and applied research are essential to accelerate the potential of AI models. The clinical management of COVID-19 has spanned various stages including anticipation, early detection, containment and mitigation, together aiming towards eventful eradication (Hu et al., 2020). There are three parameters to understand in order to access the magnitude of the risk posed by this novel coronavirus; TransmissionRate(Ro)-numberofnewlyinfected people froma singlecase; Case Fatality Rate (CFR)-percent of cases that result in death; determine whether asymptomatic transmission is possible.

Based on Chinese Newspaper, social media and other digital platform data, Hua \& Shaw (2020,in press; in Djalante, Shaw,\& DeWit,2020,p.4) analyzed the timeline of key actions taken by the government and people over three months in five different phases: the very early phase (up to 31st of December,2019), the investigation phase (up to 20th Janaury), the early identification phase (up to 31 st of January), the criticism, agony and depression phase (up to 14 February), lastly the positive and curative control phase (up to 29th February).The factors included strong governance, strict regulation, strong community vigilance, and citizen participation, wise use of big data and digital technologies. The other countries excluding China took dramatically different approaches in managing the pandemic. The variation is marked by prior experiences and preparation, early reinforcement of strict vigilance, testing and isolation, late law enforcement, strong vs. weak public awareness, self-restraint, commitments, and other factors. Some aspects of risk perception, awareness and response is a cultural issue, and powerfully linked to the socio-economic structure of the country and community (Djalante et al., 2020).

This crisis is different from many others because information about the pandemic has been widely available via governments, international organizations such as the World Health Organization, and academic institutions such as John Hopkins University. The IC's analytical role is critical now given the vast amount of information openly available and the need to help policymakers sort through and understand the data, draw conclusions, and make appropriate decisions. With today's technical tools to analyze and make sense of large qualities of data, Open Source Intelligence (OSINT) is more important than ever (Flynn, 2020). The key issue is determining the accuracy of all this data. Human Intelligence HUMINT, the type of intelligence derived from human sources, is critical to the analysis and interpretation of all this openly available data. In most cases, only a human source can tell you the future plans and intentions of leaders and adversaries, and whether and when they are lying, which is particularly important in this crisis. For instance, when the Chinese government and its leaders make pronouncements about the number of cases in China or the extent of the spread, a human source can put this in perspective and highlight any discrepancies (Flynn, 2020).

Vetting information is a persistent challenge, and there long has been a debate about which type of intelligence is the most trustworthy. Back when SIGINT (Signals Intelligence or intercepted communications) was relatively new and novel, policymakers used to say that "SIGINT does not lie" and post that it was more accurate than HUMINT. However, people lie all the time. They lie on the telephone. They lie in their text message. They lie in 
their correspondence. While human sources are certainly capable of lying and of reporting truthfully the things they heard that were actually lies, a human source is more likely to be able to provide context and an assessment of whether an individual or a government is telling the truth.

Certainly, street operations will be more complicated during the COVID-19 crisis. The streets of most cities are deserted when they would normally be packed with cars and pedestrians. As a case officer, one tactic is to blend into the crowd (Criminals do this too, although one would hesitate to draw this comparison). In this regard, Flynn (2020) writes, "If the past is any indicator, there will be the inevitable after- action reviews and commissions stood up to investigate what when wrong and issue policy prescriptions....the creations of new bureaucratic to ensure we get it...."

HUMINT involves the recruitment of sources, which in most cases is an essentially social activity. It is about building trusting relationships to the point that a potential source is willing to provide sensitive information beyond what his government or employer normally section. It would be very difficult-although not impossible-to developing a trusting relationship solely via Zoom or other impersonal means (Flynne 2020).

The World Health Organization sits atop, but the WHO does not have its own medical intelligence system. There are other medical surveillance programs gather information from news media, internet sites and other sources identify and warn about disease outbreaks. These efforts include the Global Public Health Intelligence Network, the Program for Monitoring- Emerging Diseases and Health Map (World Health Organization, 2020). The US intelligence community has for many years considered the possible threat of disease among the potential risks to national stability and security. For instance, then- Director of National Intelligence Dan Coats told Congress in January 2019 that a large- scale outbreak "could lead to massive rates of death and disability, severely affect the world economy, strain international resources, and increase calls on the United States for support." (Dahl, 2020).Some news accounts indicate U.S. intelligence agencies may have detected a new disease in China as early as November- even before Chinese authorities recognized the problem. These reports have been denied by US officials, but it is clear that by mid- January, the U.S. intelligence community had begun briefing the president on the outbreak (Dahl, 2020).

The work of Public Health Agency of Canada (PHAC) is supported by the Global Public Health Intelligence Network (GPHIN), a branch of PHAC that specializes in Open Source Intelligence (known as OSINT). OSINT combs through unclassified sources such as newspapers, but also searches social media posts and pictures, and employs technical tools including commercial satellite imagery. GPHIN has commissioned a project titled Internet - based Surveillance Informing Global Health Threats (INSIGHT). INSIGHT is mobilizing artificial intelligence experts and epidemiologists to refine GPHIN's ability to search automatically for keywords and other indicators that could signal a health emergency (Fyffe, 2020). 
Intelligence can be one source warning of the onset of a health emergency. The World Health Organization receives notification of a serious disease outbreak from the impacted country. That country must then take the comprehensive and often painful countermeasures needed to halt further transmission. Reporting from an outbreak country is not always accurate, and the required action is not always timely (Fyffe, 2020). Canada's intelligence collection and analysis assets can contribute to three necessary government capacities as a pandemic develops. First, Canadian intelligence, and that of Five Eyes intelligence partners (the United States, the United Kingdom, Australia and New Zealand) which will provide information about the outbreak. Second, it can supply insight into whether a foreign government is taking the steps that will halt domestic and global transmission. Third, intelligence analysis will help foresee the possible geopolitical consequences of a major disease outbreak (Fyffe, 2020).

It seems there are 2 different issues related to this single article;

1. One related to human ability and social sciences. Artificial intelligence and military intelligence can be integrated into one develop a different article. This can be, if more insight and analysis is made, a seminal paper for the social scientists.

2. The other is related to machine and its use during emergencies or crisis and espionage. This more related to machine (AI) organizational espionage (country against other countries). Maoist intelligence can be included here but State level intelligence operations (Nepal army intelligence and Nepal police intelligence) are not covered in this article.

\section{Intelligence agencies around the world}

Human intelligence (HUMINT) is the intellectual capability of humans, which is marked by complex cognitive feats and high levels of motivation and self-awareness (Tirri, 2011). Through intelligence, humans possess the cognitive abilities to learn, form concepts, understand, apply logic, and reason, including the capacities to recognize patterns, plan, innovate, solve problems, make decisions, retain information, and use language to communicate. HUMINT is intelligence gathered by means of interpersonal contact, as opposed to the more technical intelligence gathering disciplines such as signals intelligence (SIGINT), imagery intelligence (IMINT) and measurement and signature intelligence. NATO defines HUMINT as "a category of intelligence derived from information collected and provided by human sources." Typical HUMINT activities consist of interrogations and conversations with persons having access to information (IC Directive, 2006; in Stottlemyre, 2015, p. 585).

In general, threat intelligence refers to the formation used by an organization to better understand past, present and future threats. The four main types of threat intelligence are: strategic, tactical, technical and operational. Strategic cyber threat intelligence is a broader term usually reserved non-technical audience (Dnsstuff.com, 2019). Cyber threat 
intelligence is information about threats and threat actors that helps mitigate harmful events in cyberspace. Cyber threat intelligence sources include upon source intelligence, social media intelligence, human intelligence, technical intelligence or intelligence from the deep and dark web (CBEST, 2016).

There are many intelligence agencies around the world which are known as HUMINT, SIGINT, Communication Intelligence (COMINT) and Electronic Intelligence (ELIÑT) and IMINT. Among those agencies, SIGINT and ELIÑT are the methods an intelligence agency utilizes to target, detect, intercept, and analyze electronic signals emitted by foreign or hostile forces for both tactical and strategic intelligence purpose. COMINT and ELIÑT are the main subcategories of SIGINT. COMINT deals with communication signals between people or groups of people including voice, text and other forms of messaging. ELIÑT deals with non communication signals including telemetry from satellites missiles, remote operated vehicles including drones, radars sensors and detectors (Karaff, 2019). IMINT also pronounced as I-MINT is an intelligence gathering discipline which collects information via satellite and aerial photography. IMINT as a subset of intelligence collection management which is a subset of intelligencecyclemanagement(Imagery Intelligence,n.d.).Imagerycanbederived from visual photography, radar sensors, infrared sensors, lasers, and electro- optics. Geospatial Intelligence (GEOINT) is the analysis and visual representation of security related activities on the earth. It is produced through an integration of imagery intelligence and geospatial information (U.S. Naval War College, n.d.)

In the United States, three major disciplines of intelligence are functional, which include TECHINT, HUMINT and OSINT. TECHINT comprises technical intelligence collection systems, including IMINT, GEOINT, SIGINT, COMINT, ELINT, FISINT, and MASINT. They are used in combination with HUMINT intelligence to observe and monitor foreign government and non state actor actions and behavior. They constitute the largest portion of the US intelligence community's budget and programs (George, 2020, p. 311). OSINT involves collecting information from unclassified, publicly available sources and analyzing its significance to the US government (George, 2020, p. 308).

Counterintelligence is an activity aimed at protecting an agency's intelligence program from an opposition's intelligence service (Prunckun, 2011). It includes gathering information and conducting activities to prevent espionage, sabotage, subversion, terrorist activities, organized crime or other criminal activities, assassinations or other intelligence activities conducted for or on behalf of foreign powers, organizations or persons. Many countries will have multiple organizations such as domestic, international, and counter-terrorism. Counterintelligence could be classified into two: offensive counterintelligence and defensive counterintelligence. Offensive counterintelligence seeks to damage the long-term capability of the adversary. Defensive counterintelligence operations that succeed in breaking up a clandestine network by arresting the persons involved or by exposing their actions demonstrate that disruption is quite measurable and effective against FIS (or terrorist) if the right actions are taken (Prunckun, 2011). 


\section{Intelligence studies in Nepal}

Though the study of intelligence is very popular in the international academia, "intelligence is one of the least prioritized areas in Nepal" (Bhattrai, 2020). For this study so far, in the context of Nepal is concerned, the present author encountered with three studies of intelligence carried out by Rybak, Maharjan, \& Adhikari (2010), Gnawali (2016), and Shrestha (2018), and Jackson (2019) which are all academic based research. There are other three newspaper articles written by Bhattarai (2020), Gyawali (2020), and Singh (2019).

Among these studies, Rybak et al. (2010) have made attempts to deal with emotional intelligence, education and therapeutic communities of Nepal. They focused on particular group of children who have experienced great stress in their lives. This study shows I.Q. is not enough for children to succeed in their lives while emotional intelligence really matters to gain success. It is Gyawali (2016) who studied on the students of Kathmandu valley and analyzed on the relationship between intelligence and conflict management. They highlight that higher education is the professional education that teaches the students to enable them to perform the duty in a professional way. Higher education enables them to enhance the leadership capacity to lead the organization. Self- awareness, self- regulation, motivation, empathy and social skills as the components of emotional intelligence are significantly correlated with each other. Their findings show that the highest impact of motivation followed by social skills and self-awareness can be seen as top three emotional intelligence components. While studying emotional intelligence of college students at higher education in Nepal, Shrestha (2018) claims that emotions play a significant role in teaching and learning process. The author argues that mastery in subject matter does not make the teacher best in the eyes of students, rather emotional intelligence does. Emotional intelligence focuses on the person- centered professor or teacher. The students get to learn by building human development behaviors.

It is Bhattrai (2020) who wrote an article on intelligence and Nepal's foreign policy. In this article, he writes, inputs and insights into major decisions for the intelligence community that appear to be nil in this country. Mistakes come from misinformation. It is time to focus on building apolitical institutions as a foundation of good intelligence and good decision making of all moments by bringing the most relevant global insights into the process of analysis. Gyawali (2020) in his article stresses that artificial intelligence (AI) is an essential part in the fourth industrial revolution, and Nepal still can catch up. AI can help Nepalinits quest fordevelopment and prosperity. Thanks to the betteralgorithms, computation capabilities, and loads of data from the magic recognition tasks better than humans. Nepal has recently started AI through Naami Nepal, NIC Nepal, Fuse Machines or Paila Technologies which are attempting the gap.

Artificial intelligence was conceptualized in 1950's and has seen various phases. Singh (2019) in his study mentions that emotional intelligence in Nepal has long been limited by various stereotypes and is often viewed to be same as mental health and depression. The company known as My Emotion Matters claim that is not the same but they are certainly inter-related. They think that many health problems can be avoided if we are aware of identifying and managing our emotions (Singh, 2019). 


\section{Conclusion}

Intelligence is an integral part of human's life. Humans with no intelligence hardly survive in their habitat. From an individual to group to an organization and institution, intelligence is adopted as a tool for sustainable solution. People living in the society are facing several problems which they take a lot of effort to come up with a solution by applying intelligence as an impetus. There are various theories of intelligence developed by psychologists suggested to apply in different situations. When intelligence studies became matured, it has been borrowed by various scholars of different disciplines such as military science, conflict studies, religion, anthropology, psychology, sociology, political science, tourism and business studies.

As a broad-spectrum, intelligence studies are found to be studied from the view point of systemic, behavioral, organizational and knowledge management perspectives. It has been used as an academic subject in the field of emotion, spirituality, cultural, strategic, pandemic, tourism, business and conflict resolution or transformation for bringing peace and stability. Though there are various types of intelligence, artificial intelligence in this 21 st century has deeply influenced fields of human sphere. The symbiotic relationship between man and machine for collecting intelligence is considered as quintessential element for the solution of human's problem. Intelligence has broader field and provides vast knowledge to all human beings which is considered as a must. These days many different countries, considering the importance of intelligence, have established different intelligence agencies that play vital role of getting information in different sectors. Though intelligence have become a very popular subject across the world and the application of it is predominated by security agencies, in Nepal, intelligence studies are still at the phase of infancy in the academia. This study suggests that intelligence should be studied from interdisciplinary and integrated approaches.

\section{Acknowledgements}

First and foremost, I would like to express my sincere thanks to Mr. Nimesh Ulak, Lecturer of IST College. My gratitude goes to Prof. Dr. Shishir Subba, an eminent psychologist of Nepal, Chiranjibi Bhandari, Lecturer of DCPDS, Rajan Rai of DCPDS, Suchana Pachhai and Nishan Raj Kunwar.

\section{References}

Ang, S., Van Dyne, L., Koh, C., Ng, K. Y., Templer, K. J., Tay, C., \& Chandrasekar, N. A. (2007). Cultural intelligence: Its measurement and effects on cultural judgment and decision making, cultural adaptation and task performance. Management and Organization Review, 3(03), 335-371. doi:10.1111/j. 1740-8784.2007.00082.x.

Artificial Intelligence (n.d.). Wikipedia. https://en.wikipedia.org/wiki/Artificial_intelligence Australian Government, Department of Health (2020). Coronavirus (COVID-19) 
in Australia - Pandemic Health Intelligence Plan. [Retrieved From: https:/www. health.gov.au/news/health-alerts/novel-coronavirus-2019-ncov-health-alert/easing-ofcoronavirus-covid-19-restrictions/coronavirus-covid-19-in-australia-pandemichealth-intelligence-plan].

Bandura, A. (1977). Self-efficacy: toward a unifying theory of behavioral change. Psychological Review, 84(2), 191-215. https://doi.org/10.1037/0033295X.84.2.191.

Bandura, A. (1993). "Perceived self-efficacy in cognitive development and functioning". Educational Psychologist. 28 (2): 117-148. doi:10.1207/s15326985ep2802_3. S2CID 52256247.

Bandura, A., \& Wood, R.E. (1989). Effect of perceived controllability and performance standards on self-regulation of complex decision making. Journal of Personality and Social Psychology, 56, 805-814.

Best Jr, R. A. (2004). Homeland Security: Intelligence Support. Library of Congress Washington DC Congressional Research Service.

Bhattarai, D. (2020). Intelligence and Nepal's foreign policy. Republica. [Retrieved from: https://myrepublica.nagariknetwork.com/news/intelligence-and-nepal-s-foreignpolicy/].

Brody, N. (2000). History of Theories and Measurements of Intelligence in Handbook of Intelligence edited by Robert J. Sternberg. Cambridge University Press, UK.

CBEST (2016). CBEST intelligence-led testing: Understanding cyber threat intelligence operations. Bank of England, 2, 1-48. [Retrieved from: https://www.bankofengland. co.uk/-/media/boe/files/financial-stability/financial-sector-continuity/understanding-cyber-threat-intelligence-operations.pdf].

Cianciolo, A.T., \& Sternberg, R.J. (2004). Intelligence: A Brief History. Blackwell Brief Histories of Psychology, USA: Blackwell Publishing.

Ciarrochi, J. V., Chan, A. Y. ., \& Caputi, P. (2000). A critical evaluation of the emotional intelligence construct. Personality and Individual Differences, 28(3), 539-561. doi:10.1016/s0191-8869(99)00119-1.

Copeland, B.J. (August 11, 2020). Artificial Intelligence. Encyclopaedia Britannica. [Retrieved from: https://www.britannica.com/technology/artificial-intelligence].

COVID-19: Understanding Quarantine, Isolation and Social Distancing in a Pandemic. (April 4, 2020). healthessentials. [Retrieved from: https://health.clevelandclinic.org/ covid-19-understanding-quarantine-isolation-and-social-distancing-in-a-pandemic].

Crowne, K.A. (2013). Cultural exposure, emotional intelligence, and cultural intelligence: An exploratory study. International Journal of Cross Cultural Management, 13(1) 5-22. 
Cultural Intelligence. (n.d.). Wikipedia. [Rerieved from: https://en.wikipedia.org/wiki/ Cultural_intelligence].

Dahl, E.J. (2020). Was the coronavirus outbreak an intelligence failure? The

Conversation. [Retrieved from: https://theconversation.com/was-thecoronavirus-outbreak-an-intelligence-failure-139450].

Dalby, S. (1995). Security, intelligence, the national interest and the global environment. Intelligence and National Security, 10(4), 175-197. doi:10.1080/02684529508432332.

Dananjayan, S., \& Raj, G. M. (2020). Artificial intelligence during a pandemic: The COVID-19 example. The International Journal of Health Planning and Management. doi:10.1002/hpm.2987.

Diffen (n.d.). EQ Vs. IQ. Diffen.

[Retrieved from: https://www.diffen.com/difference/EQ vs IQ]

Djalante, R., Shaw,R.,\& DeWit,A.(2020).Building resilience against biological hazards and pandemics : COVID-19 and its implications for the Sendai Framework. Progress in Disaster Science,6,100080.

Dnsstuff.com (2019). What Is Threat Intelligence? Definition and Types. [Retrieved from: https://www.dnsstuff.com/what-is-threat-intelligence].

Dumper, K., Jenkins, W., Lacombe, A., Lovett, M., \& Perimutter, M. (n.d.). Introduction to Psychology, License.

[Retrieved from: https://opentext.wsu.edu/psych105/part/unit-1/].

Dycus, S. (2004). The role of military intelligence in homeland security. Louisiana Law Review, 64(4). Normalization of National Security Law: A Symposium.

[Retrieved from: https://digitalcommons.law.lsu.edu/cgi/viewcontent.cgi?arti-

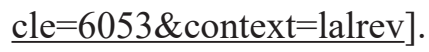

Early, P.C., \& Mosakowski, E. (2004). Cultural Intelligence. [Retrieved from: https://hbr.org/2004/10/cultural-intelligence].

ECDC (2016). Specific Privacy Statement: Epidemic intelligence Information System (EPIS). European Centre for Disease Prevention and Control. [Retrieved from: https:/www.ecdc.europa.eu/en/publications-data/epidemic-intelligence-in formation-system-epis].

Elkins, D., Hedstorm, L., Hughes, L. L., Leaf, J. A., \& Saunders, C. (1988). Toward a humanistic-phenomenological spirituality. Journal of Humanistic Psychology, 28, 5-18.

Espionage (2017). Encyclopaedia Britannica. [Retrieved from: https://www.britannica.com/topic/espionage] 
Flynn, C.C. (2020). What role does the intelligence community play in a pandemic? National Security Program. Foreign Policy Research Institute. [Retrieved from: https://www.fpri.org/article/2020/04/what-role-does-the-intelligence-communityplay-in-a-pandemic/].

Fyffe, G. (2020). A post-panedmic review of security and intelligence is essential.

[Retrieved from: https://policyoptions.irpp.org/magazines/june-2020/a-post-pan demic-review-of-security-and-intelligence-is-essential/].

Gardner, H. (1983). Frames of Mind: The Theory of Multiple Intelligence, New York: Basic Books.

Gardner, M.K. (2011). Theories of intelligence. In Bray, M.A. \& Kehle, T.J.

(Eds.) The Oxford Handbook of School Psychology,

Doi.10.1093/oxfordhb/9780195369809.013.0035.

Genç, R. (2020). Artificial intelligence and the development of smart tourism. Journal of Tourism and Hospitality Education, 10, 1-7.

https://doi.org/10.3126/jthe.v10i0.28730.

George, R.Z. (2020). Intelligence in the National Security Enterprise: An Introduction. Washington DC: Georgetown University Press.

Gardner, H. (1983). Frames of Mind, The Theory of multiple Intelligence, New York: Basic Books.

Gnawali, A. (2016). The relationship between emotional intelligence and conflict management with reference to higher education sector in Nepal. International Journal of Research in Business Studies and Management, 3(8), 19-26.

Gössling, S., Scott, D., \& Hall, C. M. (2020). Pandemics, tourism and global change: A rapid assessment of COVID-19. Journal of Sustainable Tourism, 1-20. doi:10.1080/09669582.2020.1758708.

Gowreesunkar, V.GB (2020). The social media saga: A side effect of covid 19 pandemic.

Grant, M.J. \& Booth, A. (2009). A typology of reviews: An analysis of 14th review types and associated methodologies. Health Information And Libraries Journal, 26, 91-108.

Gyawali, P.K. (2020). Nepal should gamble on artificial intelligence. The Kathmandu Post. Hickok, K. (2020).What is pandemic? [Retrieved from: https:// www.livescience.com] .

Hu, Y., Jacob, J., Parker, G.J.M., Hawkes, D.J., Hurst, J.R., \& Stoyanov, D. (2020). The challenges of deploying artificial intelligence models in a rapidly evolving pandemic. Nature Machine Intelligence, 2, 298-300.

Imagery Intelligence (n.d.). Wikipedia. https://en.wikipedia.org/wiki/Imagery intelligence. Intellectual (n.d.). Wikipedia. [Retrieved from: https://en.wikipedia.org/wiki/Intellectual]. 
International Business Publications (2016). US Military Intelligence Handbook Volume1: Strategic Information, Procedures and Developments. Int'1 Business Publications. International Journal of Health, Sciences and Research, 4(2), 165-169.

Ivanov, S., Webster,C., \& Berezina, K. (2020). Robotics in tourism and hospitality. In Xiang, Z., Fuchs, M., \& Gretzel, U. (Eds.) Handbook of e- Tourism, Springer.

Jackson, P. (2019).Intelligence in a modern insurgency: The case of the Maoist insurgency in Nepal. Intelligency and National Security, 34(7), 999-1013. DOI.10.1080.02684527.2019.1589677.

Jeffery, S.K., Deluca, J., \& Caplan, B. (Eds.) (2011). Encyclopedia of Clinical Neuropsychology.

Karaff, G. (2019). What is the difference between COMINT, SIGINT and ELINT? Online forum comment. [Retrieved from: https://www.quora.com/What-is-thedifference-between-COMINT-SIGINT-and-ELINT]

King, D.B., \& DeCicco, T.L. (2009). A Viable Model and Self-Report Measure of Spiritual Intelligence. International Journal of Transpersonal Studies. 28. 68-85. DOI: $10.24972 /$ ijts.2009.28.1.68.

Koenig, H. G., McCullough, M., \& Larson, D. B. (2000). The Handbook of Religion and Health. New York: Oxford University Press.

Lippert, R., \& O’Connor, D. (2006). Security Intelligence Networks and the Transformation of Contract Private Security. Policing and Society, 16(1), 50-66. doi:10.1080/10439460500399445

Lockdown. (n.d.). Wikipedia. [Retrieved from: https://en.wikipedia.org/wiki/Lockdown].

Masse, T. (2006). Homeland Security Intelligence: Perceptions, Statutory Definitions and Approaches. Library of Congress Washington DC Congressional Research Service.

McDowell, D. (2009). Strategic Intelligence: A Handbook for Practitioners, Managers and Users, Revised Edition, The Scarecrow Press.

Medical Laboratory Technologist (2020). Quarantine Vs Isolation: Easy way to understand difference between what is quarantine and isolation. Video file. [Retrieved From: https://www.youtube.com/watch?v=Sk44jrnhVJ4].

Meier, J.D. (2012). The power of positive intelligence - Why PQ matters more than IQ and EQ. Source of Insight.

[Retrieved from: https://sourcesofinsight.com/positive-intelligence-and-pq/]

Morens, D.M., Folkers, G.k., Fauci, A.S. (2009). What is a pandemic? The journal of infectious diseases, 2000, 1018-1021.

Murray, S. (2019). As workplaces change, is it enough to be smart? Enter AQ, the capacity to adapt that may well determine your future career success. BBC. [Retrieved from: https://www.bbc.com/worklife/article/20191106 -is-aq-more-important-than-intelligence]. 
Oleson, P.E. (2009). Book Review.Strategic Intelligence: A Handbook for ....Studies in Intelligence, 53 (3), 27-29.

Olsen, W. (n.d). Security and Intelligence Studies. Georgetown University Library. [Re trieved from: https:/guides.library.georgetown.edu/c.php?g=75520\&p=491282].

Pal, H.R., Pal A. \& Tourani, P. (2004). Theories of intelligence. Everyman's Science, xxxix, (3), 180-185.

Palmatier, R.W., Houston, M.B., \& Hulland, J. (2018). Review articles: Purpose, process and structure. Journal of the academic marketing science, 46, 1-5.

Pecht, E. \& Tishler, A. (2011).The value of military intelligence. Defense and Peace Economies, 26, 10.108010242694.2014.886435.

Phythian, M. (2012). Policing Uncertainty: Intelligence, Security and Risk. Intelligence and National Security, 27(2), 187-205. doi:10.1080/02684527.2012.661642.

Prunckun, H. (2011). A Grounded Theory of Counterintelligence. American Intelligence Journal. 29(2), 6-15.

Raymond, W. (1983). Keywords: A Vocabulary of Culture and Society, Revised Edition, New York : Oxford University Press.

Repko, A.F. (2012). Interdisciplinary Research: Process and Theory, London: Sage.

Rybak, C., Maharjan, C., \& Adhikari, A. (2013). Emotional Intelligence in the Educational and Therapeutic Community in Nepal. Journal of Education and Research. 2. 10.3126/jer.v2i0.7621.

Samal, J. (2014). A historical exploration of pandemics of some selected diseases in the world.

Segal, J., Smith, M., Robinson, L., \& Shubin, J. (2019). Improving Emotional Intelligence (EQ). Help Guide. [Retrieved from:

https:/www.helpguide.org/articles/mental-health/emotional-intelligence-eq.htm].

SetonHall University (2011/2012). Graduate Catalogue 2011/2012, 2, 1-368. [Retrieved from: https://www.shu.edu/academics/upload/SetonHall2011-2012Graduate Catalogue.pdf].

Shrestha, B. (2018). Emotional intelligence in higher education: Perspectives of Nepalese college students. [Retrieved from: https://www.westcliff.edu/wp-content/uploads/2019/08/Shrestha-2018-21.pdf].

Singh, R. (2019). Working on emotions. The Kathmandu Post.

Social Distancing (n.d.). Wikipedia. [Retrieved from:

https://en.wikipedia.org/wiki/Social_distancing].

Sternberg, R.J (1996). Successful Intelligence - How Practical and Creative Intelligence Determine Success in Life. Plume Book. 
Sternberg, R.J. (1985). Beyond IQ: A Triarchic Theory of Human Intelligence, New York: Cambridge University Press.

Sternberg, R.J. (1986). Intelligence Applied; Understanding and Increasing Your Intellectual Skills, San Diago, Harcourt Brace.

Sternberg, R.J. (1989). The Triarchic Mind: A New Theory of Human Intelligence, New York, Penguin Books.

Sternberg, R.J. (2003). A broad view of intelligence. Consulting Psychology Journal, Practice and Research, 55 (3), 139-154. doi: 10.1037/1061-4087.55.3.139.

Sternberg, R.J. (Ed.). (2018). The Nature of Human Intelligence. Cambridge University Press.

Sternberg, R.J. (1978). The theory of successful intelligence. Review of General Psychology, 3(4), 292-316.doi:10.1037/1089-2680.3.4.292.

Stottlemyre, S. A. (2015). HUMINT, OSINT, or Something New? Defining crowd sourced intelligence. International Journal of Intelligence and CounterIntelligence, 28(3), 578-589. doi:10.1080/08850607.2015.992760.

StudyMoose (2015). The value of strategic intelligence and its components. [Retrieved from: https://studymoose.com/the-value-of-strategic-intelligence-and-its-com ponents-essay]

Tirri, N. (2011). Measuring Multiple Intelligences and Moral Sensitivities in Education. Moral Development and Citizenship Education. Springer. ISBN 978-94-6091-758-5.

Trembath, J-L. (2017). Are You an Intellectual, or a Member of the Intelligentsia. [Retrieved from: https://thefamiliarstrang.com].

U.S. Naval War College. (n.d.). Intelligence Studies: Imagery/Geospatial Intelligence (IMINT/GEOINT). [Retrieved from: https://usnwc.libguides.com/c.php?g=494120\&p=3381562].

Vaishya, R., Javaid, M., Khan, I. H., \& Haleem, A. (2020). Artificial Intelligence (AI) applications for COVID-19 pandemic. Diabetes \& Metabolic Syndrome: Clinical Research \& Reviews, 14(4), 337-339. doi:10.1016/j.dsx.2020.04.012.

Vaughan, F. (2002). What is Spiritual Intelligence? Journal of Humanistic Psychology, 42(2), 16-33. doi:10.1177/0022167802422003.

Wigglesworth, C. (2014). SQ21: The twenty-one skills of spiritual intelligence. SelectBooks, Inc.

Wood, R., \& Bandura, A. (1989). Social cognitive theory of organizational management. Academy of Management Review, 14, 361-384.

World Health Organization. (2019). The introduction of mental health component into primary health care. https://apps.who.int/iris/handle/10665/37021. 
World Health Organization (2020). WHO coronavirus disease (COVID-19) Dash board. [Retrieved from: https://covid19. who.int/?gclid=Cj0KCQjwnqH7BRD dARIsACTSAdu9XNSNOPT52oFBkZG 2kEIpBIbjFxtYUyYoUY0H4fFgNd FT3wlUU0aAlQaEALw wcB].

World Health Organization. (2020). Q\&A on coronaviruses (COVID-19). [Retrieved from: https://www.who.int/emergencies/diseases/novel-coronavirus-2019/ question-and-answers-hub/q-a-detail/q-a-coronaviruses]

World Health Organization (2020). COVID-19 Strategy Update. [Retrieved From: https://www.who.int/docs/default-source/coronaviruse/covid-strategy-up date-14april2020.pdf?sfvrsn=29da3ba0_19].

Worldometer (2020). [Retrieved from: https://www.worldometers.info/coronavirus/country/nepal/].

Yepez, L. (2019). Emotional and Adversity Quotient.

[Retrieved from: https://aelyangblog.blogspot.com/2019/].

Your Dictionary. (n.d.). Diligent. [Rerieved from: https://www.yourdictionary.com].

Zohar, D., \& Marshall, I. (2000). Spiritual Intelligence: The Ultimate Intelligence. Bloomsbury. 